\title{
INHALT
}

Verzeichnis der Karten, Tabellen, Schemata

und Abbildungen $\quad 12$

$\begin{array}{ll}\text { Nachweis der Karten und Abbildungen } & 14\end{array}$

$\begin{array}{ll}\text { Verzeichnis der Abkürzungen } & 16\end{array}$

$\begin{array}{ll}\text { EINFÜHRUNG } & 19\end{array}$

Forschungsfelder und Problemstellung 21

Forschungsstand 28

Quellenkorpus und Aufbau der Arbeit $\quad 30$

TEIL 1: IM KRIEG - TOPOGRAPHIE DER ERINNERTEN ERFAHRUNG

Kapitel 1: Die Semantik der Zwänge 51

Obervolta - Territoriale Konfigurationen eines

Reservoirs kolonialer Arbeitskraft $\quad 52$

Das Instrumentarium der kolonialen „In-Wert-Setzung“ von Arbeitskraft $\quad 56$

Koloniale Zwangsarbeit, Migration und Militärdienst Motive, Optionen und Routen

Kapitel 2: Kriegsberichte und Reiseerinnerungen 91

Räume - Schauplätze und Landschaften $\quad 94$

Militärische Einrichtungen und Transitzonen 96

Die Front und ihr Jenseits $\quad 108$ 
Orte des Gedenkens

Gemeinschaften - Beziehungen in umgekehrter

Wahrnehmung

Militärische Gemeinschaften

Zivile Gemeinschaften

TEIL 2: REINTEGRATION IN DEN KOLONIALEN ALLTAG

Kapitel 3: Die Rückkehr ins Koloniale

Kapitel 4: Postmilitärische Lebensverläufe

Familiäre Strategien

Urbane Lebensstile und Innovationen

Kapitel 5: Was ist der Veteranen Heimatland? Politische Profile

Veteranen und politische Parteien -

„Als Gleiche und Freie"

Veteranen und die mère-patrie - Bindungen und

Verbindlichkeiten

FAZIT UND AUSBLICK

\section{QUELLEN- UND LITERATURVERZEICHNIS}

1. Archive

2. Mündliche und gedruckte schriftliche Quellen, audiovisuelle Zeugnisse

3. Wissenschaftliche Darstellungen

4. Elektronische Medien 
5. Tages- und Wochenzeitungen, Zeitschriften, andere Periodika

INDEX

\section{ANHANG}

Schema 1: Aufbau und Kommandostruktur der Tirailleurs Sénégalais

Schema 2: Ränge und Dienstgrade der französischen

Infanterie

Itinerar eines voltaischen FFL-Kombattanten

Verzeichnis der durchgeführten Interviews 